Handb Clin Neurol. 2013 ; 117: 365-370. doi:10.1016/B978-0-444-53491-0.00029-8.

\title{
Sympathetic neuroimaging
}

\author{
DAVID S. GOLDSTEIN ${ }^{*}$ \\ Clinical Neurocardiology Section, Clinical Neurosciences Program, Division of Intramural \\ Research, National Institute of Neurological Disorders and Stroke, National Institutes of Health, \\ Bethesda, MD, USA
}

\section{INTRODUCTION}

Until recently, clinical laboratory means to test patients with known or suspected abnormalities of the autonomic nervous system consisted of physiological independent manipulations (e.g., heat exposure, the Valsalva maneuver, tilt table testing) and physiological dependent measures (e.g., sweating, blood pressure, heart rate and heart rate variability, skin and core temperature, forearm vascular resistance, skin electrical conductance, cutaneous humidity, microcirculatory blood flow, skeletal muscle sympathetic microneurography). Since the late 1970s, clinical research on autonomic disorders has also included neurochemical measures (e.g., plasma norepinephrine during supine rest and orthostasis, norepinephrine spillover, dihydroxyphenylglycol, neuronal nicotinic receptor antibodies) and physiological or neurochemical effects of neuropharmacological agents (e.g., tyramine, clonidine, yohimbine, desipramine, trimethaphan, isoprenaline (isoproterenol), glucagon, reboxetine, and acetylcholine in the quantitative sudomotor axon reflex test).

Sympathetic neuroimaging provides an important supplement to physiological, neurochemical, and neuropharmacological approaches in the evaluation of patients with clinical autonomic disorders. Sympathetic neuroimaging using planar scintigraphy became available in the 1980s (Wieland et al., 1981), followed by imaging using single-photon emission computed tomography (SPECT) and positron emission tomography (PET).

This chapter discusses concepts underlying sympathetic neuroimaging, summarizes methods and agents used, highlights some applications of clinical sympathetic neuroimaging, and emphasizes the utility of sympathetic neuroimaging to detect cardiac sympathetic denervation in Lewy body diseases.

Neuroimaging assessments can be categorized in terms of anatomic, functional nonspecific, and functional specific. Examples of anatomic neuroimaging are computed tomography and magnetic resonance imaging of the brain. Functional nonspecific approaches include functional magnetic resonance imaging and assessments of regional perfusion or metabolism by PET after administration of ${ }^{18} \mathrm{~F}$-fluorodeoxyglucose, ${ }^{13} \mathrm{~N}$-ammonia, or ${ }^{15} \mathrm{O}$-water. None

*Correspondence to: Dr. David S. Goldstein, NINDS, NIH, 10 Center Drive MSC-1620, 9000 Rockville Pike, Building 10 Room 5N220, Bethesda, MD 20892-1620, USA. iPhone: +1-301-675-1110, Tel: +1-301-496-2103, Fax: +1-301-402-0180, goldsteind@ninds.nih.gov. 
of these specifically visualizes sympathetic innervation or function. Functional specific methods examine transporters, receptors, or uptake and storage of neurotransmitters. For instance, measurement of putamen ${ }^{18} \mathrm{~F}$-DOPA-derived radioactivity enables assessment of dopaminergic innervation.

\section{SYMPATHETIC NEUROIMAGING METHODS AND AGENTS}

Almost all sympathetic neuroimaging to date has involved visualization of noradrenergic innervation in the left ventricular myocardium. This is because the heart is a relatively large, solid, homogeneous organ that possesses a high concentration of sympathetic nerve fibers, which surround the myocardial cells. Cardiac sympathetic images therefore resemble myocardial perfusion scans. Other thoracic organs and tissues possess much lower concentrations of sympathetic nerves.

SPECT scanning after injection of the sympathomimetic amine ${ }^{123} \mathrm{I}$ metaiodobenzylguanidine ( ${ }^{123} \mathrm{I}-\mathrm{MIBG}$ ) constitutes by far the most commonly used means worldwide to assess cardiac sympathetic innervation. The principle underlying ${ }^{123}$ I-MIBG scanning (as well as sympathetic neuroimaging by PET imaging agents) is not binding of the tracer-labeled compound to receptors on target cells but physical translocation into the sympathetic nerves via the cell membrane norepinephrine transporter and then subsequent active transport of the cytosolic compound into vesicles via the vesicular monoamine transporter. Thus, sympathetic neuroimaging depends on radiolabeling of vesicles in sympathetic nerves.

Cardiac sympathetic neuroimaging by ${ }^{123}$ I-MIBG scanning has been used extensively in Japan, to a lesser extent in Europe, and hardly at all in the US. The dearth of American experience seems to be the result of a vicious cycle involving lack of insurance coverage because of lack of clinical trials because of lack of availability because of lack of insurance coverage. ${ }^{123}$ I-MIBG scanning is available at many centers in the US for diagnostic evaluation of pheochromocytoma, since third party payers generally cover this application.

${ }^{123}$ I-MIBG, an analog of the sympathomimetic amine guanethidine, differs structurally from norepinephrine, the neurotransmitter that mediates sympathetic regulation of the cardiovascular system. Injected MIBG undergoes a different fate from catecholamines such as norepinephrine. These differences must be considered when interpreting changes in ${ }^{123} \mathrm{I}-$ MIBG-derived radioactivity in terms of sympathetic neuronal function. First, MIBG is not as avidly or selectively removed by sympathetic nerves as are catecholamines. Second, MIBG that is taken up into the sympathoneural axoplasm is not a substrate for monoamine oxidase, the main enzyme metabolizing cytosolic catecholamines in sympathetic nerves. Third, MIBG is not a substrate for catechol- $O$-methyltransferase, a major enzyme metabolizing catecholamines in non-neuronal cells. The metabolic fate of MIBG remains poorly understood.

Since ${ }^{123} \mathrm{I}$ is not a positron-generating isotope, the usual method for detecting ${ }^{123} \mathrm{I}$-MIBGderived radioactivity is SPECT, not PET scanning. After intravenous injection of ${ }^{123} \mathrm{I}$ MIBG, a relatively long time is required for obtaining interpretable images. ${ }^{123}$ I-MIBG 
"uptake" is measured about 15-30 minutes after injection of the tracer. Since by then myocardial uptake of tracer-labeled catecholamines is already complete, ${ }^{123}$ I-MIBG-derived radioactivity in the "uptake" phase actually probably reflects a complex combination of transmembrane neuronal uptake, intraneuronal vesicular uptake, loss of radioactivity via exocytosis, and loss of radioactivity from vesicular leakage back into the cytosol and reverse transport from the cytosol into the extracellular fluid. ${ }^{123}$ I-MIBG "washout" is measured 3-4 hours after tracer injection. Radioactivity concentrations in SPECT scans are difficult to calibrate, and myocardial concentrations of ${ }^{123}$ I-MIBG-derived radioactivity are usually expressed in terms of heart:mediastinum (H:M) ratios. In patients with coronary arterial or microvascular narrowing, as in atherosclerotic cardiovascular disease and diabetes mellitus, low $\mathrm{H}: \mathrm{M}$ ratios of ${ }^{123} \mathrm{I}$-MIBG-derived radioactivity might reflect decreased delivery of the imaging agent by blood perfusion; ${ }^{123}$ I-MIBG SPECT studies rarely take myocardial perfusion into account.

Based on H:M ratios of ${ }^{123}$ I-MIBG-derived radioactivity, decreased uptake, increased washout, or both have been reported in many disorders, including cardiovascular disorders (congestive heart failure, myocardial infarction, ventricular arrhythmias, dilated cardiomyopathy, Chagas disease, essential hypertension with left ventricular hypertrophy, Brugada syndrome), neurodegeneration (Parkinson disease, pure autonomic failure, Lewy body dementia), emotional distress, liver or kidney failure, and hypothyroidism. In general, attenuated uptake and accelerated washout are associated with relatively poor prognosis (Fanciulli et al., 2013; Kinbara et al., 2013). This pattern may reflect decreased vascular delivery of ${ }^{123}$ I-MIBG, increased cardiac sympathetic nerve traffic, decreased vesicular sequestration of cytoplasmic amines, or decreased activity of the cell membrane norepinephrine transporter abnormalities that may coexist.

PET scanning offers potential advantages over SPECT scanning. Spatial resolution is better, the amount of injected radioactivity is smaller, radioactivity concentrations in tissues can be measured in absolute terms, and analyses of curves relating tissue radioactivity detected by PET scanning over time (time-activity curves) can yield information about not only innervation but also function. Several agents have been developed for sympathetic neuroimaging by PET scanning. These include ${ }^{11} \mathrm{C}$-epinephrine, ${ }^{18} \mathrm{~F}$-dopamine, ${ }^{11} \mathrm{C}$ hydroxyephedrine, and ${ }^{18} \mathrm{~F}$-metaraminol. ${ }^{11} \mathrm{C}$-Epinephrine and ${ }^{18} \mathrm{~F}$-dopamine are catecholamines, whereas ${ }^{11} \mathrm{C}$-hydroxyephedrine and ${ }^{18} \mathrm{~F}$-metaraminol are noncatecholamine sympathomimetic amines. All are investigational agents, and none has been approved yet for clinical diagnostic purposes.

Although ${ }^{18} \mathrm{~F}$-DOPA, which is used to assess striatal dopaminergic innervation in neurodegenerative disorders such as Parkinson disease, is converted to ${ }^{18} \mathrm{~F}$-dopamine in sympathetic nerves, ${ }^{18} \mathrm{~F}-\mathrm{DOPA}$ is not a sympathetic neuroimaging agent. Structurally, ${ }^{18} \mathrm{~F}$ DOPA is a neutral amino acid, not a catecholamine, and so ${ }^{18} \mathrm{~F}-\mathrm{DOPA}$ is taken up by all cells via the neutral amino acid transporter. ${ }^{18} \mathrm{~F}$-DOPA in non-neuronal cells may be converted to ${ }^{18} \mathrm{~F}$-dopamine by L-aromatic-amino-acid decarboxylase, but this is probably a minor fate compared to incorporation into peptides or proteins and enzymatic breakdown independent of catecholamine formation. After intravenous injection of ${ }^{18} \mathrm{~F}-\mathrm{DOPA}$, plasma 
concentrations of ${ }^{18} \mathrm{~F}$-dopamine are too low to enable visualization of cardiac sympathetic innervation.

\section{SYMPATHETIC NEUROIMAGING IN DYSAUTONOMIAS}

The term, "dysautonomia," has been used to refer to conditions in which altered activity of one or more components of the autonomic nervous system adversely affects health. The following discussion focuses on dysautonomias that involve functional abnormalities or loss of sympathetic noradrenergic nerves.

\section{Diabetic neuropathy}

One of the first forms of dysautonomia to be evaluated by clinical sympathetic neuroimaging was diabetic autonomic neuropathy. In general, patients with diabetic autonomic neuropathy have decreased $\mathrm{H}: \mathrm{M}$ ratios of ${ }^{123}$ I-MIBG-derived radioactivity, especially in delayed images. A factor complicating interpretation of the results in terms of sympathetic denervation is that patients with diabetic autonomic neuropathy have a high frequency of coronary arterial and arteriolar narrowing, so that low H:M ratios ${ }^{123}$ I-MIBG-derived radioactivity may reflect a combination of denervation and decreased delivery of the tracer to sympathetic nerves via coronary hypoperfusion. Analyses of ${ }^{123}$ I-MIBG SPECT scans rarely adjust ${ }^{123}$ I-MIBGderived radioactivity for perfusion in the same regions of interest. ${ }^{11} \mathrm{C}-$ Hydroxyephedrine PET scanning, with perfusion assessed by ${ }^{13} \mathrm{NH}_{3}$ scanning in the same subjects, has revealed imaging evidence for heterogeneously decreased sympathetic innervation in relatively distal (apical, inferior, lateral) cardiac segments (Allman et al., 1993). A study of painful diabetic neuropathy reported decreased local concentrations of perfusion-adjusted ${ }^{18} \mathrm{~F}$-dopaminederived radioactivity, along with decreased entry of norepinephrine into the venous drainage, indicating local sympathetic denervation (Tack et al., 2002).

\section{Heart failure with risk of sudden death}

Many studies have reported abnormalities of $\mathrm{H}: \mathrm{M}$ ratios ${ }^{123} \mathrm{I}-\mathrm{MIBG}$-derived radioactivity in patients with heart failure. Treatments that successfully alleviate the failure generally improve the sympathetic neuroimaging abnormalities. Accelerated loss of ${ }^{123}$ I-MIBGderived radioactivity is associated with a worse prognosis (Kasama et al., 2008).

Patients with heart failure and low cardiac ejection fractions have an increased risk of sudden cardiac death. In such patients, a low H:M ratio of ${ }^{123}$ I-MIBG-derived radioactivity at 4 hours after tracer injection is an independent, adverse prognostic factor (Jacobson et al., 2010). It is possible that ${ }^{123}$ I-MIBG cardiac sympathetic neuroimaging might help identify a subgroup of heart failure patients at high risk for sudden death from ventricular fibrillation, in whom implantation of an cardioverter-defibrillator would be warranted.

\section{Bilateral thoracic sympathectomies}

Upper thoracic sympathectomy is used to treat several disorders - especially hyperhidrosis; however, sympathetic nerve fibers emanating from thoracic ganglia also innervate the heart. ${ }^{18} \mathrm{~F}$-Dopamine PET scanning was used to test whether unilateral or bilateral upper thoracic sympathectomy affects cardiac sympathetic innervation in humans (Moak et al., 
2005). Low rates of entry of norepinephrine into the arm venous drainage verified upper limb sympathectomy. Patients with bilateral sympathectomy had low septal myocardial concentrations of ${ }^{18} \mathrm{~F}$-dopamine-derived radioactivity compared with normal volunteers but greater radioactivity than in patients with pure autonomic failure. Patients with unilateral sympathectomy had normal radioactivity. Bilateral upper thoracic sympathectomy therefore partly decreases cardiac sympathetic innervation density.

\section{Complex regional pain syndrome}

Patients with complex regional pain syndrome (formerly called reflex sympathetic dystrophy) have posttraumatic pain disproportionate to the injury and spreading beyond the distribution of any single peripheral nerve. Sympathetic neurocirculatory function and the role of sympathetic postganglionic nerve traffic in maintaining the pain was examined in patients with unilateral complex regional pain syndrome (Goldstein et al., 2000b). Most patients had had the condition for more than 1 year. Perfusion-adjusted ${ }^{18} \mathrm{~F}$-dopaminederived radioactivity was if anything higher on the affected side. Therefore, chronic complex regional pain syndrome is not attended by evidence of local sympathetic denervation.

\section{Chronic orthostatic intolerance}

In postural tachycardia syndrome (often referred to as POTS) and repeated neurocardiogenic presyncope, chronic orthostatic intolerance occurs without persistent sympathetic neurocirculatory failure. Patients with postural tachycardia syndrome or neurocardiogenic presyncope underwent measurements of neurochemical indices of cardiac release, reuptake, and synthesis of norepinephrine based on entry of norepinephrine into the cardiac venous drainage (cardiac norepinephrine spillover) and measurement of left ventricular myocardial sympathetic innervation density using ${ }^{18} \mathrm{~F}$-dopamine PET scanning. Mean cardiac norepinephrine spillover was increased in POTS and decreased in neurocardiogenic presyncope, compared to healthy control subjects (Goldstein et al., 2002). Both patient groups had normal myocardial ${ }^{18} \mathrm{~F}$-dopamine-derived radioactivity. POTS and neurocardiogenic presyncope therefore differ in tonic cardiac sympathetic function, with increased cardiac norepinephrine release in the former and decreased release in the latter; however, both conditions involve normal density of myocardial sympathetic innervation. Because POTS and neurocardiogenic presyncope include specific abnormalities of cardiac sympathetic function even while at supine rest, both can be considered forms of dysautonomia.

\section{Hypertrophic cardiomyopathy}

Patients with hypertrophic cardiomyopathy often have clinical findings consistent with increased cardiac sympathetic outflow. The status of sympathetic innervation specifically in hypertrophic regions was examined by PET scanning using the perfusion imaging agent ${ }^{13} \mathrm{~N}$-ammonia and the sympathoneural imaging agent ${ }^{18} \mathrm{~F}$-dopamine in patients with hypertrophic cardiomyopathy and in healthy control subjects (Li et al., 2000). At all time points, the ${ }^{18} \mathrm{~F}:{ }^{13} \mathrm{~N}$ ratio was lower in hypertrophied than in nonhypertrophied regions, indicating decreased neuronal uptake of catecholamines in the hypertrophied myocardium. Decreased uptake could reflect local relative hypoinnervation, decreased numbers of neuronal uptake sites, or metabolic limitations on cell membrane transport. By enhancing 
norepinephrine delivery to adrenoceptors for a given amount of sympathetic nerve traffic, decreased neuronal uptake might help explain major clinical features of hypertrophic cardiomyopathy, including increased risk of sudden cardiac death.

\section{Familial dysautonomia}

Familial dysautonomia involves incomplete development of the sympathetic nervous system. Adult familial dysautonomia patients underwent thoracic ${ }^{18} \mathrm{~F}$-dopamine PET scanning, to determine the status of sympathetic innervation of the heart (Goldstein et al., 2008). The patients had decreased uptake and accelerated loss of ${ }^{18} \mathrm{~F}$-dopamine-derived radioactivity in the interventricular myocardial septum and ventricular free wall, compared to untreated controls. Desipramine-treated controls had decreased uptake but normal loss of radioactivity. Familial dysautonomia therefore seems to involve cardiac noradrenergic hypoinnervation. Since accelerated loss of ${ }^{18} \mathrm{~F}$-dopamine-derived radioactivity cannot be explained by decreased neuronal uptake alone, the disease may also involve augmented norepinephrine loss from extant terminals, either from increased exocytosis or decreased vesicular uptake.

\section{ASSOCIATION OF CARDIAC NORADRENERGIC DENERVATION WITH LEWY BODY DISEASES}

Lewy body diseases such as Parkinson disease, dementia with Lewy bodies, and pure autonomic failure are characterized by intraneuronal precipitates of the protein a-synuclein and are now therefore subsumed under the heading of synucleinopathies. Multiple system atrophy is also considered to be a form of synucleinopathy; however, in multiple system atrophy a-synuclein deposits are found in glial cells rather than neurons (Wakabayashi et al., 1998).

Lewy body synucleinopathies are associated with imaging evidence of substantial cardiac sympathetic denervation, both by ${ }^{123}$ I-MIBG SPECT (Satoh et al., 1999) and by ${ }^{11} \mathrm{C}$ hydroxyephedrine (Raffel et al., 2006) and ${ }^{18}$ F-dopamine PET (Goldstein et al., 1997, 2000a) scanning. In these diseases, cardiac noradrenergic denervation has been confirmed by profoundly decreased tyrosine hydroxylase immunoreactivity in epicardial nerves (Orimo et al., 2002, 2006). In contrast, most (but not all) patients with multiple system atrophy have neuroimaging evidence for normal cardiac sympathetic innervation (Druschky et al., 2000; Braune, 2001; Orimo et al., 2001, 2007). Although imaging evidence for cardiac sympathetic denervation does not exclude multiple system atrophy, the finding of normal cardiac sympathetic innervation probably does exclude Parkinson disease with orthostatic hypotension.

Nonmotor findings associated with Parkinson disease, such as dementia, loss of sense of smell (anosmia), REM behavior disorder, baroreflex failure, and orthostatic hypotension, have all been reported to be associated with cardiac noradrenergic denervation (Orimo et al., 2005; Lee et al., 2006; Miyamoto et al., 2006; Yoshita et al., 2006; Goldstein et al., 2009; Kashihara et al., 2010).

When in the course of Parkinson disease does cardiac sympathetic denervation occur? Based on the concept proposed by Braak for the pathogenetic sequence (Braak et al., 2004), there 
is early deposition of a-synuclein in the olfactory bulb and autonomic nerves in the stomach, with subsequent ascending pathology in the autonomic ganglia, dorsal motor nucleus of the vagus in the caudal medulla, rostral ventrolateral medulla, pontine locus coeruleus, midbrain substantia nigra, and finally diffuse lesions in the cortex. This concept predicts that imaging evidence of cardiac sympathetic denervation may be a premotor biomarker of Parkinson disease. Although such evidence can precede the movement disorder by several years (Goldstein et al., 2007) and is apparent in at least some patients with $d e$ novo Parkinson disease (Oka et al., 2006, 2011) or incidental Lewy body disease (Orimo et al., 2008b), the frequency and consistency of this abnormality as an antecedent of parkinsonism have not yet been determined (Goldstein et al., 2011a).

Cardiac sympathetic neuroimaging and postmortem neuropathological findings have linked a-synucleinopathy with noradrenergic denervation in Lewy body diseases (Orimo et al., 2008b). Thus, patients with familial Parkinson disease from abnormalities of the gene encoding a-synuclein have cardiac sympathetic denervation (Goldstein et al., 2001; Singleton et al., 2004; Orimo et al., 2008a). The pathological changes seem to progress in a retrograde, centripetal manner.

Bases for the association of a-synucleinopathy with catecholaminergic denervation remain obscure. According to the "catecholaldehyde hypothesis," catecholaldehydes produced from enzymatic deamination of cytosolic catecholamines exert cytotoxic effects because of oxidative stress and oligomerization of a-synuclein (Burke et al., 2008; Panneton et al., 2010), resulting in deleterious positive feedback loops. Consistent with this view, postmortem putamen tissue from patients with Parkinson disease contains increased levels of dihydroxyphenylacetaldehyde, relative to dopamine (Goldstein et al., 2011b).

Especially because of the utility of cardiac sympathetic neuroimaging in distinguishing Parkinson disease from multiple system atrophy in patients with clinical evidence of central neurodegeneration and orthostatic hypotension, sympathetic neuroimaging seems a valuable addition to physiological, neuropharmacological, and neurochemical approaches in the diagnostic evaluation of selected patients with autonomic and neurodegenerative disorders (Goldstein and Sharabi, 2009).

\section{References}

Allman KC, Stevens MJ, Wieland DM, et al. Noninvasive assessment of cardiac diabetic neuropathy by carbon-11 hydroxyephedrine and positron emission tomography. J Am Coll Cardiol. 1993; 22:1425-1432. [PubMed: 8227801]

Braak H, Ghebremedhin E, Rub U, et al. Stages in the development of Parkinson's disease-related pathology. Cell Tissue Res. 2004; 318:121-134. [PubMed: 15338272]

Braune $\mathrm{S}$. The role of cardiac metaiodobenzylguanidine uptake in the differential diagnosis of parkinsonian syndromes. Clin Auton Res. 2001; 11:351-355. [PubMed: 11794715]

Burke WJ, Kumar VB, Pandey N, et al. Aggregation of alpha-synuclein by DOPAL, the monoamine oxidase metabolite of dopamine. Acta Neuropathol. 2008; 115:193-203. [PubMed: 17965867]

Druschky A, Hilz MJ, Platsch G, et al. Differentiation of Parkinson's disease and multiple system atrophy in early disease stages by means of I-123-MIBG-SPECT. J Neurol Sci. 2000; 175:3-12. [PubMed: 10785250] 
Fanciulli A, Strano S, Colosimo C, et al. The potential prognostic role of cardiovascular autonomic failure in alpha-synucleinopathies. Eur J Neurol. 2013; 20:231-235. [PubMed: 22834919]

Goldstein DS, Sharabi Y. Neurogenic orthostatic hypotension: a pathophysiological approach. Circulation. 2009; 119:139-146. [PubMed: 19124673]

Goldstein DS, Holmes C, Cannon RO 3rd, et al. Sympathetic cardioneuropathy in dysautonomias. N Engl J Med. 1997; 336:696-702. [PubMed: 9041100]

Goldstein DS, Holmes C, Li ST, et al. Cardiac sympathetic denervation in Parkinson disease. Ann Intern Med. 2000a; 133:338-347. [PubMed: 10979878]

Goldstein DS, Tack C, Li ST. Sympathetic innervation and function in reflex sympathetic dystrophy. Ann Neurol. 2000b; 48:49-59. [PubMed: 10894215]

Goldstein DS, Li ST, Kopin IJ. Sympathetic neurocirculatory failure in Parkinson disease: evidence for an etiologic role of alpha-synuclein. Ann Intern Med. 2001; 135:1010-1011. [PubMed: 11730415]

Goldstein DS, Holmes C, Frank SM, et al. Cardiac sympathetic dysautonomia in chronic orthostatic intolerance syndromes. Circulation. 2002; 106:2358-2365. [PubMed: 12403667]

Goldstein DS, Sharabi Y, Karp BI, et al. Cardiac sympathetic denervation preceding motor signs in Parkinson disease. Clin Auton Res. 2007; 17:118-121. [PubMed: 17334896]

Goldstein DS, Eldadah B, Sharabi Y, et al. Cardiac sympathetic hypo-innervation in familial dysautonomia. Clin Auton Res. 2008; 18:115-119. [PubMed: 18498023]

Goldstein DS, Sewell L, Holmes C. Association of anosmia with autonomic failure in Parkinson disease. Neurology. 2009; 74:245-251.

Goldstein DS, Sewell L, Sharabi Y. Autonomic dysfunction in PD: a window to early detection? J Neurol Sci. 2011a; 310:118-122. [PubMed: 21529844]

Goldstein DS, Sullivan P, Holmes C, et al. Catechols in post-mortem brain of patients with Parkinson disease. Eur J Neurol. 2011b; 18:703-710. [PubMed: 21073636]

Jacobson AF, Senior R, Cerqueira MD, et al. Myocardial iodine-123 meta-iodobenzylguanidine imaging and cardiac events in heart failure. Results of the prospective ADMIRE-HF (AdreView Myocardial Imaging for Risk Evaluation in Heart Failure) study. J Am Coll Cardiol. 2010; 55:2212-2221. [PubMed: 20188504]

Kasama S, Toyama T, Sumino H, et al. Prognostic value of serial cardiac ${ }^{123}$ I-MIBG imaging in patients with stabilized chronic heart failure and reduced left ventricular ejection fraction. J Nucl Med. 2008; 49:907-914. [PubMed: 18483106]

Kashihara K, Imamura T, Shinya T. Cardiac ${ }^{123}$ I-MIBG uptake is reduced more markedly in patients with REM sleep behavior disorder than in those with early stage Parkinson's disease. Parkinsonism Relat Disord. 2010; 16:252-255. [PubMed: 20097595]

Kinbara T, Hayano T, Otani N, et al. Iodine-123 metaiodobenzylguanidine imaging can predict future cardiac events in Japanese patients with Parkinson's disease. Ann Nucl Med. 2013; 27:123-131. [PubMed: 23086545]

Lee PH, Yeo SH, Kim HJ, et al. Correlation between cardiac ${ }^{123}$ I-MIBG and odor identification in patients with Parkinson's disease and multiple system atrophy. Mov Disord. 2006; 21:1975-1977. [PubMed: 16960860]

Li ST, Tack CJ, Fananapazir L, et al. Myocardial perfusion and sympathetic innervation in patients with hypertrophic cardiomyopathy. J Am Coll Cardiol. 2000; 35:1867-1873. [PubMed: 10841237]

Miyamoto T, Miyamoto M, Inoue Y, et al. Reduced cardiac ${ }^{123}$ I-MIBG scintigraphy in idiopathic REM sleep behavior disorder. Neurology. 2006; 67:2236-2238. [PubMed: 17190953]

Moak JP, Eldadah B, Holmes C, et al. Partial cardiac sympathetic denervation after bilateral thoracic sympathectomy in humans. Heart Rhythm. 2005; 2:602-609. [PubMed: 15922266]

Oka H, Mochio S, Onouchi K, et al. Cardiovascular dysautonomia in de novo Parkinson's disease. J Neurol Sci. 2006; 241:59-65. [PubMed: 16325862]

Oka H, Toyoda C, Yogo M, et al. Cardiovascular dysautonomia in de novo Parkinson's disease without orthostatic hypotension. Eur J Neurol. 2011; 18:286-292. [PubMed: 20602633]

Orimo S, Ozawa E, Oka T, et al. Different histopathology accounting for a decrease in myocardial MIBG uptake in PD and MSA. Neurology. 2001; 57:1140-1141. [PubMed: 11571358] 
Orimo S, Oka T, Miura H, et al. Sympathetic cardiac denervation in Parkinson's disease and pure autonomic failure but not in multiple system atrophy. J Neurol Neurosurg Psychiatry. 2002; 73:776-777. [PubMed: 12438492]

Orimo S, Amino T, Itoh Y, et al. Cardiac sympathetic denervation precedes neuronal loss in the sympathetic ganglia in Lewy body disease. Acta Neuropathol (Berl). 2005; 109:583-588. [PubMed: 15933869]

Orimo S, Amino T, Takahashi A, et al. Cardiac sympathetic denervation in Lewy body disease. Parkinsonism Relat Disord. 2006; 12(Suppl 2):S99-S105.

Orimo S, Kanazawa T, Nakamura A, et al. Degeneration of cardiac sympathetic nerve can occur in multiple system atrophy. Acta Neuropathol (Berl). 2007; 113:81-86. [PubMed: 17089131]

Orimo S, Uchihara T, Nakamura A, et al. Cardiac sympathetic denervation in Parkinson's disease linked to SNCA duplication. Acta Neuropathol (Berl). 2008a; 116:575-577. [PubMed: 18751989]

Orimo S, Uchihara T, Nakamura A, et al. Axonal alpha-synuclein aggregates herald centripetal degeneration of cardiac sympathetic nerve in Parkinson's disease. Brain. 2008b; 131:642-650. [PubMed: 18079166]

Panneton WM, Kumar VB, Gan Q, et al. The neurotoxicity of DOPAL: behavioral and stereological evidence for its role in Parkinson disease pathogenesis. PLoS One. 2010; 5:e15251. [PubMed: 21179455]

Raffel DM, Koeppe RA, Little R, et al. PET measurement of cardiac and nigrostriatal denervation in parkinsonian syndromes. J Nucl Med. 2006; 47:1769-1777. [PubMed: 17079809]

Satoh A, Serita T, Seto M, et al. Loss of ${ }^{123}$ I-MIBG uptake by the heart in Parkinson's disease: assessment of cardiac sympathetic denervation and diagnostic value. J Nucl Med. 1999; 40:371375. [PubMed: 10086697]

Singleton A, Gwinn-Hardy K, Sharabi Y, et al. Association between cardiac denervation and parkinsonism caused by alpha-synuclein gene triplication. Brain. 2004; 127:768-772. [PubMed: 14736756]

Tack CJ, van Gurp PJ, Holmes C, et al. Local sympathetic denervation in painful diabetic neuropathy. Diabetes. 2002; 51:3545-3553. [PubMed: 12453912]

Wakabayashi K, Yoshimoto M, Tsuji S, et al. Alpha-synuclein immunoreactivity in glial cytoplasmic inclusions in multiple system atrophy. Neurosci Lett. 1998; 249:180-182. [PubMed: 9682846]

Wieland DM, Brown LE, Rogers WL, et al. Myocardial imaging with a radioiodinated norepinephrine storage analog. J Nucl Med. 1981; 22:22-31. [PubMed: 7452352]

Yoshita M, Taki J, Yokoyama K, et al. Value of ${ }^{123}$ I-MIBG radioactivity in the differential diagnosis of DLB from AD. Neurology. 2006; 66:1850-1854. [PubMed: 16801649] 